\title{
PENGUKURAN KINERJA KARYAWAN DENGAN HUMAN RESOURCES SCORECARD DI PONDOK PESANTREN ASSYAFIIYAH TAMBERU BATUMARMAR PAMEKASAN
}

Faiqoh Bahjah Lailatus Siyami ${ }^{1}$, Terisa Sapta Dasyanti ${ }^{2}$

Mahasiswa Program Studi Magister Manajemen Fakultas Ekonomi dan Bisnis Universitas Trunojoyo Madura

\begin{tabular}{|c|c|}
\hline INFO ARTIKEL & Abstract \\
\hline \begin{tabular}{ll}
\multicolumn{3}{l}{ Sejarah Artikel: } \\
Diterima $\quad:$ \\
Diperbaiki $:$ \\
Disetujui $\quad:$
\end{tabular} & \multirow[b]{2}{*}{$\begin{array}{l}\text { Pondok Pesantren (Islamic Boarding School) is one of the oldest pedagogical } \\
\text { institutions in Indonesia. Pondok Pesantren Assyafiiyah is one of Islamic } \\
\text { BoardingSchools located in the area of Madura. To be a productive Islamic } \\
\text { Boarding School (i.e.a boarding school which fits the need of pesantren), } \\
\text { Assyafiiyah Islamic Boarding School needs to measure the performance of the } \\
\text { employee. In this case, it is known as Board Performance which involves hu- } \\
\text { man resources, strategy, and performance. To produce a superior educational } \\
\text { institution, the implementation of Human Resource Scorecard method that } \\
\text { has a positive and significant effect on the institution of Assyafiiyah Islamic } \\
\text { Boarding School is very necessary. It is used as an analysis of human resource } \\
\text { performance. It is expected that this kind performance measurement system } \\
\text { (i.e. Human Resource Scorecard) is able to provide the best solution in im- } \\
\text { proving employee performance. Try Out is given and conducted on the insti- } \\
\text { tution to measure the performance system achievemet of its human resources. } \\
\text { Therefore, the Key Performance Indicators which does not reach the target can } \\
\text { be discovered. In other words, such kind of Try Out can be used to analyze the } \\
\text { necessary refinement and improvement of the Key Performance Indicators } \\
\text { previously mentioned. Based on the status quo, there are two major problems } \\
\text { in this research: 1) how is the mapping of Human Resourse Scorecard?; and 2) } \\
\text { what are the factors influencing the optimalization of Board Performance in } \\
\text { Assyafiiyah Islamic Boarding School through Human Resource Scorecard? }\end{array}$} \\
\hline Keywords: & \\
\hline & Abstraks \\
\hline Kata Kunci: & \multirow[b]{2}{*}{$\begin{array}{l}\text { Pondok Pesantren adalah salah satu lembaga pendidikan tertua di } \\
\text { Indonesia. } \\
\text { Pondok Pesantren Assyafiiyah merupakan salah satu pesantren yang } \\
\text { berlokasi di daerah Pantura Madura. Untuk menjadi Pondok pesantren } \\
\text { yang mampu menghasilkan santri yang produktif dan sesuai dengan } \\
\text { kebutuhan yang diinginkan lembaga, maka Pondok pesantren } \\
\text { Assyafiiyah perlu melakukan pengukuran kinerja karyawan, yang } \\
\text { dalam hal ini di sebut dengan kinerja Pengurus yang mengaitkan } \\
\text { orang (SDM), strategi, dan kinerja. Untuk menghasilkan lembaga } \\
\text { pendidikan yang unggul dengan penerapan metode human resource } \\
\text { scorecard yang berpengaruh positif dan signifikan terhadap lembaga } \\
\text { pendidikan Pondok pesantren Assyafiiyah sebagai analisis kinerja } \\
\text { sumber daya manusia. Salah satu system pengukuran kinerja yang } \\
\text { sistematis berbasis sumber daya manusia yang akan dilakukan ini } \\
\text { diharapkan lebih memberikan solusi terbaik dalam peningkatan } \\
\text { kinerja pegawai, yaitu Human Resource Scorecard. Try Out dilakukan } \\
\text { pada institusi ini untuk mengetahui gambaran pencapaian kinerja } \\
\text { system sumber daya manusianya, sehingga dapat diketahui Key } \\
\text { Performance Indicators yang tidak memenuhi target, yang }\end{array}$} \\
\hline DOI: & \\
\hline
\end{tabular}




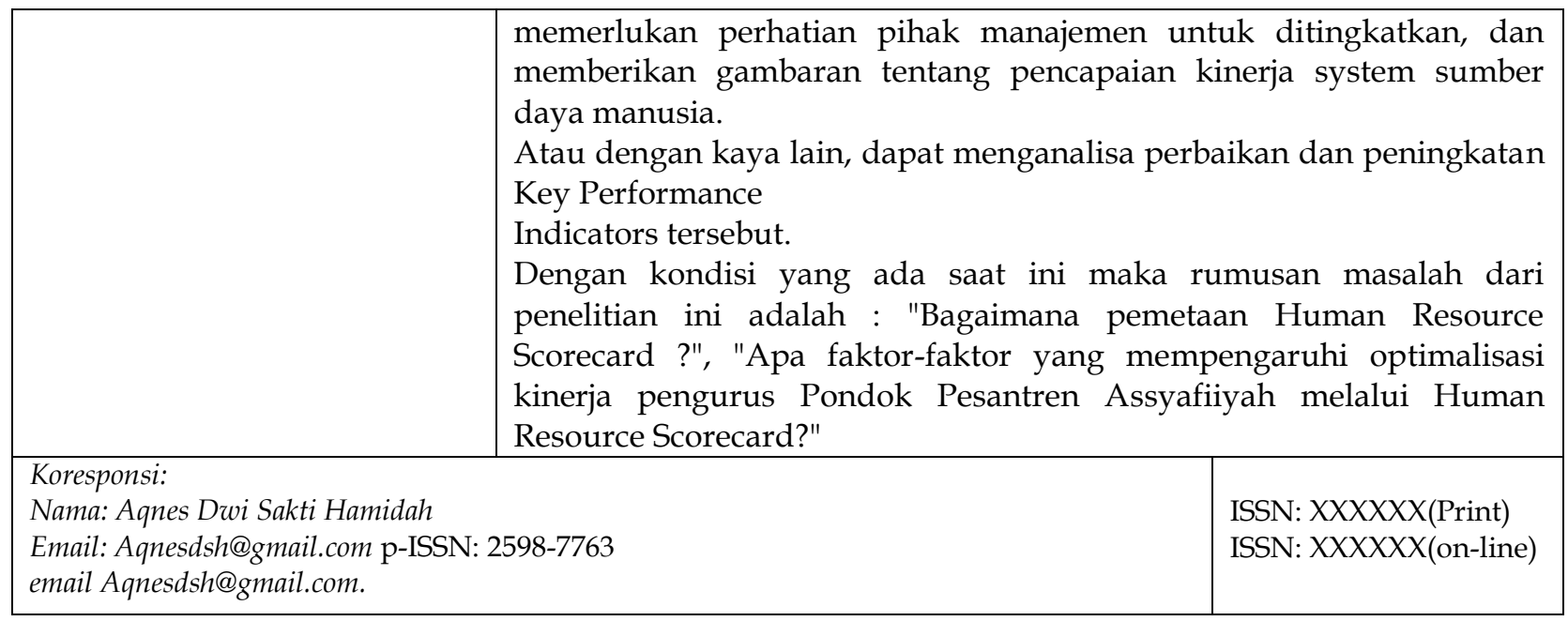

\section{PENDAHULUAN}

Pondok pesantren adalah sebuah pendidikan tradisional yang para siswanya

tinggal bersama dan belajar di bawah bimbingan guru yang lebih dikenal dengan sebutan kiai dan mempunyai asrama untuk tempat menginap santri. Santri tersebut berada dalam kompleks yang juga menyediakan masjid untuk beribadah, ruang untuk belajar, dan kegiatan keagamaan lainnya. Kompleks ini biasanya dikelilingi oleh tembok untuk dapat mengawasi keluar masuknya para santri sesuai dengan peraturan yang berlaku. Pondok Pesantren merupakan dua istilah yang menunjukkan satu pengertian. Pesantren menurut pengertian dasarnya adalah tempat belajar para santri, sedangkan pondok berarti rumah atau tempat tinggal sederhana terbuat dari bambu. Di samping itu, kata pondok mungkin berasal dari Bahasa Arab Funduq yang berarti asrama atau hotel. Di Jawa termasuk Sunda dan Madura umumnya digunakan istilah pondok dan pesantren, sedang di Aceh dikenal dengan Istilah dayah atau rangkang atau menuasa, sedangkan di Minangkabau disebut surau. Pesantren juga dapat dipahami sebagai lembaga pendidikan dan pengajaran agama, umumnya dengan cara nonklasikal, di mana seorang kiai mengajarkan ilmu agama Islam kepada santri-santri berdasarkan kitab-kitab yang ditulis dalam bahasa Arab oleh Ulama Abad pertengahan, dan para santrinya biasanya tinggal di pondok (asrama) dalam pesantren tersebut.

Mengenai asal-usul dan latar belakang pesantren di Indonesia terjadi perbedaan pendapat di kalangan para ahli sejarah. Pertama, pendapat yang menyebutkan bahwa pesantren berakar pada tradisi Islam sendiri, yaitu tradisi tarekat. Pandangan ini dikaitkan dengan fakta bahwa penyebaran Islam di Indonesia pada awalnya banyak dikenal dalam bentuk kegiatan tarekat dengan dipimpin oleh kyai. Salah satu kegiatan

tarekat adalah melakukan ibadah di masjid di bawah bimbingan kyai. Untuk keperluan tersebut, kyai menyediakan ruang- ruang khusus untuk menampung para santri sebelah kiri dan kanan masjid. Para pengikut tarekat selain diajarkan amalan-amalan tarekat mereka juga diajarkan kitab agama dalam berbagai cabang ilmu pengetahuan agama Islam.

Kedua, menyatakan bahwa kehadiran pesantren di Indonesia diilhami oleh lembaga pendidikan "kuttab", yakni lembaga pendidikan pada masa kerajaan bani Umayyah. Pada tahap berikutnya lembaga ini mengalami perkembangan pesat, karena didukung oleh masyarakat serta adanya rencana-rencana yang harus dipatuhi oleh pendidik dan anak didik.

Ketiga, pesantren yang ada sekarang merupakan pengambil alihan dari sistem pesantren orangorang Hindu di Nusantara pada masa sebelum Islam. Lembaga ini dimaksudkan sebagai tempat mengajarkan ajaran-ajaran agama Hindu serta tempat membina kader-kader penyebar agama tersebut. Pesantren merupakan kreasi sejarah anak bangsa setelah mengalami persentuhan budaya dengan budaya pra-Islam. Pesantren merupakan sistem pendidikan Islam yang memiliki kesamaan dengan sistem pendidikan Hindu Budha. Pesantren disamakan dengan mandala 
dan asrama dalam khazanah lembaga pendidikan pra-Islam.

Hasil penelusuran sejarah menunjukkan bahwa cikal bakal pendirian pesantren pada awal ini terdapat di daerah-daerah sepanjang pantai utara Jawa, seperti Giri (Gresik), Ampel Denta (Surabaya), Bonang (Tuban), Kudus, Lasem, dan Cirebon. Kota- kota tersebut pada waktu itu merupakan kota kosmopolitan yang menjadi jalur penghubung perdagangan dunia, sekaligus tempat persinggahan para pedagang dan mubalig Islam yang datang dari Jazirah Arab seperti Persia dan Irak.

Pesantren di Indonesia tumbuh dan berkembang sangat pesat. Sepanjang abad ke-

18 sampai dengan abad ke -20, pesantren sebagai lembaga pendidikan Islam semakin dirasakan keberadaannya oleh masyarakat secara luas, sehingga kemunculan pesantren di tengah masyarakat selalu direspons positif oleh masyarakat. Di antara elemen-elemen pokok atau unsur pesantren yaitu, kiai, pondok (asrama), masjid, santri, pengajaran kitab kuning.

Saat ini pesantren bertansformasi bukan sekedar sebagai lembaga pendidikan yang hanya mengajarkan ilmu agama. Pondok pesantren telah meninggalkan perspektif kuno yang menganggap bahwa pendidikan di pondok pesantren terkesan kolot dan ketinggalan zaman. Banyak sekali pondok pesantren di Indonesia yang telah melengkapi dunia kependidikan di dalamnya dengan ilmu-ilmu umum seperti, ilmu sains, ilmu kejuruan, ilmu bela diri, kesenian, kerajinan, pramuka, tekhnik, ekonomi, dan lain sebagainya. Hal tersebut sekiranya dimaksudkan bahwa generasi Islam tidak hanya harus menguasai pengetahuan agama seputar membaca kitab dan tentang hukum- hukum Islam, melainkan generasi Islam juga harus mampu bersaing sampai kancah Internasional.

Perkembangan seperti ini tidak luput dari adanya peran penting dari pemimpin

pesantren yang dikenal dengan sebutan "Kiai" yang dalam struktural di sebut "Pengasuh". Peranan Kiai dalam pondok pesantren itu sangatlah penting karena keberadaan Kiai yaitu menjadi palang pintu atau menjadi salah satu ujung tombak dari keberhasilan dalam berlangsungnya semua kegiatan. Salah satu tugas atau peran Kiai yaitu harus bisa mengelola konflik dalam Pondok pesantren yang dipimpinnya sehingga setiap konflik itu bisa diselesaikan dengan baik dan tidak ada yang merasa dirugikan. Kiai sebagai pimpinan Pondok pesantren adalah seseorang yang bekerja melalui orang

lain dengan mengoordinasikan kegiatankegiatan mereka guna mencapai sasaran organisasi.

Posisi Kiai menjadi sangat krusial dan diharapkan mempunyai peranan dalam meningkatkan serta menjaga keseimbangan dalam Pondok pesantren. Bak panglima perang di era global yang sarat kompetisi, seorang Kiai mengemban tugas menjamin ketersediaan, keakuratan, ketepatan, dan keamanan informasi serta pengaturan organisasi yang baik serta yang dibutuhkan oleh Pondok pesantren untuk mencapai tujuan Pondok pesantren sekaligus meningkatkan eksistensi Pondok pesantren di tengah-tengah lingkungannya. Keberhasilan menjalankan tugas ini mensyaratkan Kiai mempunyai kemampuan multidisiplin, antara lain: teknologi, bisnis, dan manajemen, serta kepemimpinan.

Selain Kiai yang menjadi pimpinan dalam Pondok pesantren, Pondok pesantren juga mempunyai garis struktural yang sama pentingnya untuk menjalankan rancangan kegiatan yang telah diputuskan oleh Kiai. Garis struktural ini mempunyai peran sebagai pelaksana segala jenis kegiatan yang telah menjadi kegiatan Pondok pesantren, pelaksana ini dalam Pondok pesantren disebut sebagai Pengurus atau garis kepengurusan. Setiap bidangnya mempunyai peran yang berbeda-beda. Hal ini sama dengan organisasi pada umumnya yang memetakkan beberapa bidang dengan Job Description yang berbeda agar tidak terjadi benturan fungsi dan tugas.

Lokasi penelitian ini ada mengambil pada salah satu pondok pesantren di Madura yang terletak di wilayah Pantura. Tepatnya di desa Tamberu Agung Kecamatan Batumarmar Kabupaten Pamekasan. Sedikit sejarah dari berdirinya pondok adalah Pondok Pesantren Assyafiiyah untuk pertama kalinya di dirikan oleh Almarhum KH. Moh. Syafi'uddin, sekaligus sebagai pengasuh yang pertama. Tidak ada keterangan resmi, tanggal, bulan dan tahun berapa tepatnya pondok pesantren Assyafiiyah didirikan, karena cikal bakal dari pesantren ini adalah markas pejuang sabil pada masa penjajahan 
sampai perjuangan mempertahankan kemerdekaan.

Namun demikian, beberapa sumber menyatakan, bahwa Almarhum KH. Moh. Syafi'uddin mulai bermukim di lokasi Pondok Pesantren Assyafiiyah yang sekarang ini, sejak tahun 1943. Awal-awal berdirinya, tidak ada fasilitas apa-apa di Pondok Pesantren Assyafiiyah ini, kecuali Musholla, asrama santri yang terbuat dari gedek, dan sebuah sumur sebagai sarana untuk bersuci. Pun tidak ada kegiatan apa-apa selain sorogan dan bandongan Al-Qur'an serta kitab-kitab kuning yang semuanya di asuh langsung oleh Almarhum $\mathrm{KH}$. Moh. Syafi'uddin. Pondok pesantren Assyafiiyah adalah salah satu Pondok Syalafiyah yang berpedoman pada Kaidah "Menjaga tradisi lama yang baik dan mengambil tradisi baru yang baik pula", hal ini sesuai dengan apa yang diterapkan di Pondok pesantren ini. Pondok Pesantren Salaf, salafi atau salafiyah adalah tipe pondok pesantren tradisional di Indonesia. Kebalikan dari pesantren salaf adalah ponpes modern (kholaf, ashriyah). Istilah salaf di sini tidak ada hubungannya dengan gerakan pembaruan Islam garis keras Wahabi yang kerap disebut dengan gerakan salafi.

Beberapa ciri khas dari pesantren salaf adalah, pertama, adanya penekanan pada penguasaan kitab klasik atau kitab kuning (kutub atturats - ثن ارنتا ب). Kedua, masih diberlakukannya sistem pengajian sorogan, wetonan, bandongan dalam proses kegiatan belajar mengajar (KBM) santri. Ketiga, saat ini walaupun pesantren salaf memperkenalkan sistem jenjang kelas, disebut juga dengan sistem klasikal, namun materi pelajaran tetap berfokus pada kitab-kitab kuning alias kitab klasik. Keempat, secara umum hubungan emosional kyai-santri di pesantren salaf jauh lebih dekat

dibanding pesantren modern. Hal ini karena kyai menjadi figur sentral: sebagai edukator karakter, pembimbing rohani dan pengajar ilmu agama.

\section{METODE}

Studi ilmiah ini menggunakan pendekatan kualitatif deskriptif yaitu penelitian yang dilakukan sesuai dengan data empiris dan fakta di lapangan. Nizar, dalam Iriani Ismail, 2017, mengatakan bahwa tujuan penelitian kualitatif deskriptif adalah membuat deskripsi, gambaran atau lukisan secara sistematis, faktual dan akurat
Untuk menjadi Pondok pesantren yang mampu menghasilkan santri yang produktif dan sesuai dengan kebutuhan yang diinginkan lembaga, maka Pondok pesantren Assyafiiyah perlu melakukan pengukuran kinerja karyawan, yang dalam hal ini di sebut dengan kinerja Pengurus yang mengaitkan orang (SDM), strategi, dan kinerja. Untuk menghasilkan lembaga pendidikan yang unggul dengan penerapan metode human resource scorecard yang berpengaruh positif dan signifikan terhadap lembaga pendidikan Pondok pesantren Assyafiiyah sebagai analisis kinerja sumber daya manusia. Dalam proses menata diri menjadi institusi yang unggul, maka harus mampu mengembangkan system sumber daya manusia yang ada agar dapat secara efektif dan efisien meningkatkan kualitas sumber daya manusianya, serta menigkatkan kontribusinya dalam strategi lembaga. Oleh karena itu, pengembangan system sumber daya manusia yang sistematis, terstruktur, dan terukur terus dilakukan. Salah satu system pengukuran kinerja yang sistematis berbasis sumber daya manusia yang akan dilakukan ini diharapkan lebih memberikan solusi terbaik dalam peningkatan kinerja pegawai, yaitu Human Resource Scorecard. Try Out dilakukan pada institusi ini untuk mengetahui gambaran pencapaian kinerja system sumber daya manusianya, sehingga dapat diketahui Key Performance Indicators yang tidak memenuhi target, yang memerlukan perhatian pihak manajemen untuk ditingkatkan, dan memberikan gambaran tentang pencapaian kinerja system sumber daya manusia. Atau dengan kaya lain, dapat menganalisa perbaikan dan peningkatan Key Performance Indicators tersebut.

Dengan kondisi yang ada saat ini maka rumusan masalah dari penelitian ini adalah

: "Bagaimana pemetaan Human Resource Scorecard ?", "Apa faktor-faktor yang mempengaruhi optimalisasi kinerja pengurus Pondok Pesantren Assyafiiyah melalui Human Resource Scorecard?"

mengenai fakta- fakta, sifat-sifat serta hubungan antar fenomena yang diselidiki. Ini akan memberikan

gambaran secara jelas mengenai analisis kinerja karyawan Pondok Pesantren Assyafiiyah menggunakan metode human resources scorecard. 
Langkah-Langkah dalam studi ini, adalah sebagai berikut:

a. Tahap Identifikasi

Tahap ini dimulai dengan mengidentifikasi dan merumuskan permasalahan, dimana permasalahan dalam penelitian ini adalah belum adanya pengukuran kinerja sumber daya manusia lain secara terintegrasi selain yang diatrur pemerintah dengan menggunakan SKP. Dengan demikian output yang dihasilkan dari penelitian ini adalah rancangan dan hasil try out pengukuran kinerja pegawai berdasarkan konsep Human Resource Scorecard. Selanjutnya dilanjutkan dengan studi pustaka dan studi lapangan.

b. Tahap Perancangan

Pada tahap perancangan ini, dilakukan proses perancangan indikator kinerja kontribusi SDM dengan menggunakan konsep Human Resource Scorecard.

- Mengidentifikasi strategi SDM perusahaan.

Langkah yang dilakukan adalah mengidentifikasi visi, misi, dan strategi perusahaan, sampai penurunan kepada strategi SDM perusahaan, dan sasaran SDM perusahaan.

- Penentuan strategic objectives masing-masing perspektif.

Seluruh strategi dan sasaran tersebut diklasifikasikan ke dalam strategic goal yang kemudian diterjemahkan menjadi hubungan sebab akibat ke dalam 4 perspektif dalam Human Resource Scorecard yang terdiri dari financial, customer, internal business process, dan learning and growth, di mana strategic goal ini diuraikan dalam strategic objectives masing- masing perspektif.

- Penentuan Key Performance Indicators masing-masing Strategic

Objectives

Langkah selanjutnya adalah menentukan Key Performance Indicators tiap-tiap strategic objectives nya yang merepresentasikan indikator kinerja keberhasilan sistem sumber daya manusia.

- Validasi

Untuk mengetahui apakah sistem pengukuran kinerja yang dirancang sudah mewakili sistem organisasi sumber daya manusia yang ada, dan sesuai dengan kebutuhan SDM institusi, maka dilakukan proses validasi kepada pihak manajemen. Bila tidak valid, maka dilakukan redesign.

c. Tahap pengukuran

Tahap pengukuran diawali dari pembobotan, di mana pembobotan bersama-sama data aktual dan target digunakan untuk try out pengukuran kinerja yaitu penentuan skor pencapaian kinerja sistem sumber daya manusia (dan traffic light system).

\section{- Pembobotan}

Pembobotan dilakukan dengan metode Fuzzy, untuk mengetahui bobot tingkat kepentingan masing-masing perspektif, strategic objectives, dan Key Performance Indicators. Hasil pembobotan digunakan untuk perhitungan skor pencapaian kinerja sistem sumber daya manusia.

- Perhitungan skor pencapaian kinerja sistem sumber daya manusia

Total dari bobot dikalikan skor masingmasing Key Performance Indicators dalam strategic objectivesnya, menghasilkan skor pencapaian kinerja strategic objectivesnya (Kaplan, 2000). Total bobot dikalikan

skor masing-masing strategic objectives dalam perspektifnya, menghasilkan skor pencapaian kinerja perspektif tersebut. Begitu pula total bobot dikalikan skor pencapaian kinerja tiap-tiap perspektif, menghasilkan skor pencapaian kinerja sistem sumber daya manusia secara keseluruhan. d. Tahap Analisa dan Kesimpulan

Berdasarkan pencapaian kinerja sistem sumber daya manusia yang telah dihasilkan, kemudian dianalisa menggunakan Traffic Light System, untuk mengidentifikasi indikator kinerja yang perlu mendapat perhatian serius. Pada tahap akhir penelitian ini, ditarik kesimpulan hasil rancangan dan try out pencapaian kinerja saat ini dan saran untuk perbaikan dan peningkatan kinerja sistem sumber daya manusianya di masa mendatang.

\section{HASIL DAN PEMBAHASAN}

1. Visi dan Misi Pondok Pesantren Assyafiiyah

Visi Pondok pesantren Assyafiiyah

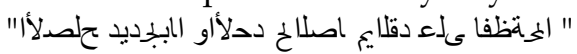

Misi Pondok pesantren Assyafiiyah, yaitu :

a. Mendidik dan memberi contoh dengan budi pekerti yang baik.

b. Mensyiarkan nilai-nilai agama Islam kepada masyarakat.

c. Mempertahankan tradisi lama dan memberikan sentuhan pembaharuan yang lebih baik.

d. Menggerakkan semangat dakwah Rasulullah.

e. Mencetak generasi yang mukmin dan mukhlis, yang mempunyai kemampuan keilmuan keagamaan yang mendalam, mampu mengembangkan dan menerapkan ajaran Islam 
secara utuh (kaffah), serta bertanggung jawab pada agama, bangsa, dan negara.

2. Tujuan Didirikannya Pondok Pesantren Assyafiiyah

a. Terwujudnya generasi yang Berakhlaqur Karimah dan menghargai nilai- nilai ilmu agama dan kemanusiaan.

b. Terbentuknya generasi yang berpengetahuan luas dan berkhidmat pada masyarakat.

c. Melindungi secara legal terhadap kegiatankegiatan positif yang ada di dalam di luar lingkungan pesantren.

d. Meningkatkan kualitas akhlaq, ibadah, skill, dakwah para santri dan para alumni.

e. Menyiapkan santri yang mempunyai kemampuan keilmuan agama mendalam serta mampu mengembangkannya

f. Menyiapkan santri sebagai kader bangsa yang tangguh, memiliki

keimanan dan ketakwaan kepada Allah SWT, berakhlak mulia, terampil, dan beramal shaleh.

\section{Struktur Organisasi}

Institusi ini memiliki sebanyak 52 kepengurusan yang terdiri dari :

a. 3 Pengurus Atas

b. 3 Pengurus Pelaksana Harian

c. 4 Ketua Bidang

d. 7 kepengurusan Asrama terdiri dari 6 Asrama

Sebagai institusi atau lembaga pendidikan, beberapa sarana dan prasarana sudah tersedia seperti :

a. Asrama Santri

b. Musholla Ubudiah

c. Musholla Kegiatan d. Kantor Pesantren

e. Koperasi Pesantren

f. Markas Tahfidzul Quran g. Dapur Santri

h. Kamar Mandi

i. Sound Sistem KegiatanGedung Sekolah, meliputi : Madrasah Diniyah, SMP Islam, Madrasah Aliyah.

j. Kantor masing-masing sekolah

k. Wi-fi

1. Aula Sekolah

m. Kios Phone

\section{Key Performance Indicator}

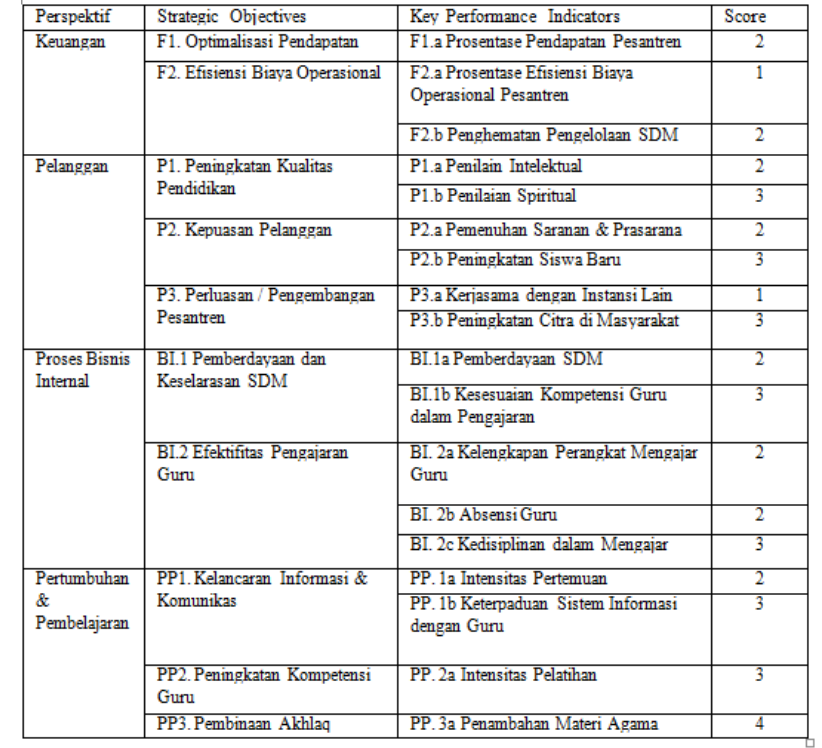

Skor Kuesioner Menggunakan Skala Likert 1 s/d 4 :

1 : Sangat Tidak Baik

2 : Tidak Baik

3 : Baik

4 : Sangat Baik

Pengukuran Kinerja karyawan berbasis Human

Resources Scorecard dan faktor-faktor pembobotannya :

1. Perspektif Keuangan

Skor, bobot, dan skor terbobot kinerja karyawan dari perspektif keuangan dapat dilihat pada table berikut :

Tabel perbandingan perspektif keuangan

\begin{tabular}{|c|c|c|c|c|}
\hline F1a & $\begin{array}{c}\text { F1a } \\
1,00000\end{array}$ & & $\begin{array}{c}\text { F2a } \\
5,00000\end{array}$ & $\begin{array}{c}\text { F2b } \\
3,00000\end{array}$ \\
\hline F2a & 0,20000 & & 1,00000 & 0,33333 \\
\hline $\mathrm{F} 2 \mathrm{~b}$ & 0,33333 & & 3,00000 & 1,00000 \\
\hline Jumlah & 1,53333 & & 9,00000 & 4,33333 \\
\hline \multicolumn{5}{|c|}{ Table Normalisasi perspektif keuangan } \\
\hline & F1a & F2a & $\mathrm{F} 2 \mathrm{~b}$ & BOBOT \\
\hline F1a & 0,65217 & 0,55555 & 0,69230 & 0,63334 \\
\hline F2a & 0,13043 & 0,11111 & 0,07692 & 0,10615 \\
\hline $\mathrm{F} 2 \mathrm{~b}$ & 0,21738 & 0,33333 & 0,23076 & 0,26049 \\
\hline
\end{tabular}

\section{Perspektif Pelanggan}

Skor, bobot, dan skor terbobot kinerja karyawan dari perspektif Pelanggan dapat dilihat pada table berikut :

\begin{tabular}{|c|c|c|c|c|c|c|}
\hline \multicolumn{7}{|c|}{ Tabel perbandingan perspektif Pelanggan } \\
\hline & P1a & P1b & $\mathrm{P} 2 \mathrm{a}$ & $\mathrm{P} 2 \mathrm{~b}$ & P3a & $\mathrm{P} 3 \mathrm{~b}$ \\
\hline P1a & 1,00000 & 1,00000 & 3,00000 & 5,00000 & 3,00000 & 5,00000 \\
\hline P1b & 1,00000 & 1,00000 & 0,20000 & 0,33333 & 0,33333 & 0,20000 \\
\hline P2a & 0,33333 & 5,00000 & 1,00000 & 0,33333 & 0,33333 & 0,20000 \\
\hline $\mathrm{P} 2 \mathrm{~b}$ & 0,20000 & 3,00000 & 3,00000 & 1,00000 & 0,20000 & 0,33333 \\
\hline $\mathrm{P} 3 \mathrm{a}$ & 0,33333 & 3,00000 & 3,00000 & 5,00000 & 1,00000 & 1,00000 \\
\hline $\mathrm{P} 3 \mathrm{~b}$ & 0,20000 & 5,00000 & 5,00000 & 3,00000 & 1,00000 & 1,00000 \\
\hline Jumlah & 3,06666 & 18,00000 & 15,20000 & 14,66666 & 5,86666 & 7,73333 \\
\hline \multicolumn{7}{|c|}{ Table Normalisasi perspektif pelanggan } \\
\hline
\end{tabular}




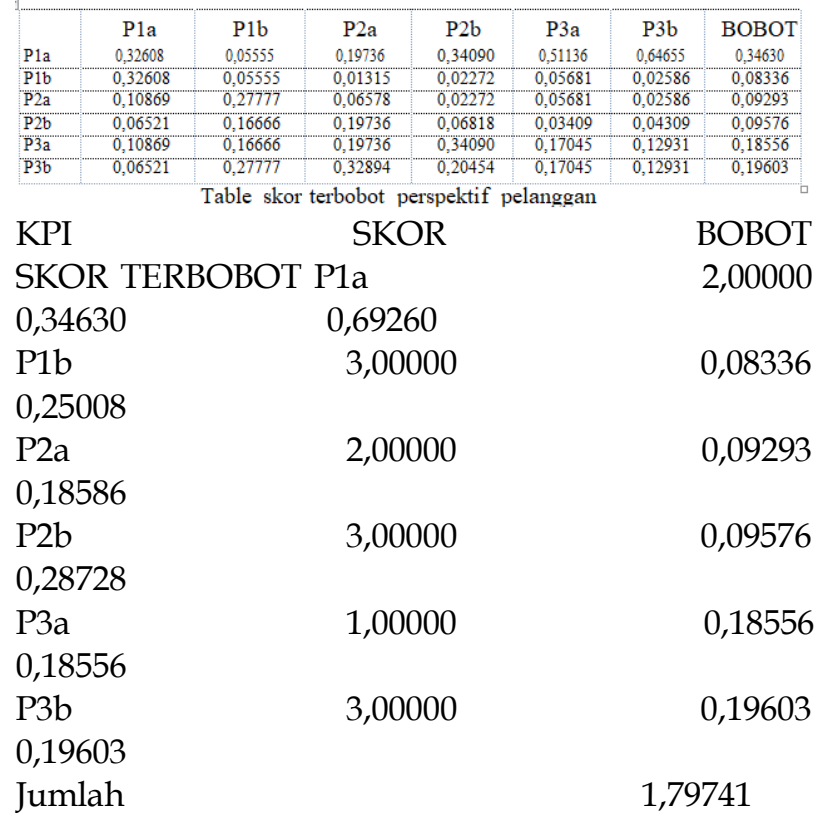

Dari table tersebut terlihat bahwa skor terbobot perspektif Pelanggan sebesar 1,79741.

3. Perspektif Proses Bisnis Internal

Skor, bobot, dan skor terbobot kinerja karyawan dari perspektif Bisnis

Internal dapat dilihat pada table berikut:

Tabel perbandingan perspektif Bisnis Internal

$\begin{array}{llll}\text { BI } 1 a & \text { BI } 1 b & \text { BI } 2 a & \text { BI } 2 b\end{array}$ BI 2c

$\begin{array}{ccccc}\text { BI 1a } & & 1,00000 & 5,00000 & 3,00000 \\ \begin{array}{c}\text { 3,00000 } \\ \text { BI 1b }\end{array} & 5,00000 & & & \\ \begin{array}{c}\text { 0,33333 } \\ \text { BI 2a }\end{array} & 0,33333 & 0,20000 & 1,00000 & 0,33333 \\ \begin{array}{c}\text { 0,20000 } \\ \text { BI 2b }\end{array} & 0,33333 & 0,33333 & 3,00000 & 1,00000 \\ \begin{array}{c}\text { 1,00000 } \\ \text { BI 2c }\end{array} & 0,20000 & 0,33333 & 3,00000 & 5,00000 \\ \begin{array}{c}\text { 5,00000 } \\ \begin{array}{c}\text { Jumlah } \\ \text { 1,00000 }\end{array}\end{array} & 0,20000 & 3,00000 & 3,00000 \\ \begin{array}{c}\text { 12,33333 } \\ \text { 9,53333 }\end{array} & 6,86666 & 15,00000\end{array}$

Table Normalisasi perspektif Bisnis Internal

BI 1a BI 1b BI 2a $\quad$ BI 2b $\quad$ BI 2c BOBOT BI 1a $0,48387 \quad 0,33333 \quad 0,24324$ $0,31468 \quad 0,72815 \quad 0,42065$

BI 1b 0,09677 0,06666 0,02702 0,03496 $0,04854 \quad 0,05479$

BI 2a $\quad 0,16128 \quad 0,20000 \quad 0,08108$

$0,02097 \quad 0,04854 \quad 0,10237$

BI 2b $\quad 0,16128 \quad 0,20000 \quad 0,40540 \quad 0,10489$

$0,02412 \quad 0,17913$

BI 2c $\quad 0,09677 \quad 0,20000 \quad 0,24324 \quad 0,52447$

$0,14563 \quad 0,24202$

\begin{tabular}{|l|c|c|c|}
\multicolumn{5}{|c|}{ Table skor terbobot perspektif Bisnis Internal } \\
\hline KPI & SKOR & BOBOT & SKOR TERBOBOT \\
\hline BI 1a & 3,00000 & 0,42065 & 1,26195 \\
\hline BI 1b & 2,00000 & 0,05479 & 0,10958 \\
\hline BI 2a & 3,00000 & 0,10237 & 0,30711 \\
\hline BI 2b & 2,00000 & 0,17913 & 0,35827 \\
\hline BI 2c & 3,00000 & 0,24202 & 0,72606 \\
\hline
\end{tabular}

Jumlah

2,76297

Dari table tersebut terlihat bahwa skor terbobot perspektif Bisnis internal sebesar 2,76297.

4. Perspektif Pertumbuhan \& Pembelajaran

Skor, bobot, dan skor terbobot kinerja karyawan dari perspektif pertumbuhan

\& pembelajaran dapat dilihat pada table berikut :

\begin{tabular}{|l|c|c|c|c|c|c|}
\multicolumn{6}{|c|}{ Tabel perbandingan perspektif pertumbuhan \& pembelajaran } \\
\hline \multicolumn{1}{|c|}{ PP 1a } & PP 1b & PP 2a & PP 3a & PP 3b \\
\hline PP 1a & 1,00000 & 3,00000 & 3,00000 & 5,00000 & 5,00000 \\
\hline PP 1b & 0,33333 & 1,00000 & 0,33333 & 1,00000 & 0,20000 \\
\hline PP 2a & 0,33333 & 3,00000 & 1,00000 & 0,33333 & 0,33333 \\
\hline PP 3a & 0,20000 & 1,00000 & 3,00000 & 1,00000 & 0,33333 \\
\hline PP 3b & 0,20000 & 5,00000 & 3,00000 & 3,00000 & 1,00000 \\
\hline Jumlah & 2,06666 & 13,00000 & 10,33333 & 10,33333 & 6,86666 \\
\hline
\end{tabular}

\begin{tabular}{|c|c|c|c|c|c|c|c|}
\hline \multicolumn{2}{|r|}{ PP 1a } & \multirow{2}{*}{$\begin{array}{l}\mathrm{PP} 1 \mathrm{~b} \\
0.23076\end{array}$} & \multirow{2}{*}{$\begin{array}{l}\mathrm{PP} 2 \mathrm{a} \\
0.29032\end{array}$} & \multirow{2}{*}{$\begin{array}{l}\mathrm{PP} 3 \mathrm{a} \\
0.48387\end{array}$} & \multirow{2}{*}{$\begin{array}{l}\mathrm{PP} 3 \mathrm{~b} \\
0.72815\end{array}$} & \multicolumn{2}{|l|}{ BOBOT } \\
\hline PP 1a & 0,48387 & & & & & 0,44339 & \\
\hline PP 1 ba & 0.16128 & 0.07692 & 0.03225 & 0.09677 & 0.02912 & 0,07926 & \\
\hline PP $2 a$ & 0,16128 & 0.23076 & 0.09677 & 0.03225 & 0.04854 & 0.11392 & \\
\hline PP $3 a$ & 0.09677 & 0.07692 & 0.29032 & 0.09677 & 0.04854 & 0.12186 & \\
\hline PP $3 b$ & 0.09677 & 0.38461 & 0.29032 & 0.29032 & 0.14563 & 0.24153 & \\
\hline \multicolumn{8}{|c|}{ Table skor terbobot perspektif pertumbuhan \& pengembangan } \\
\hline \multicolumn{2}{|c|}{ KPI } & \multirow{2}{*}{\multicolumn{2}{|c|}{$\begin{array}{l}\text { SKOR } \\
200000\end{array}$}} & \multirow{2}{*}{\multicolumn{2}{|c|}{$\begin{array}{c}\text { BOBOT } \\
0,44339\end{array}$}} & SKC & R TERBOBOT \\
\hline \multicolumn{2}{|c|}{ PP 1a } & & & & & & 0,88678 \\
\hline \multicolumn{2}{|c|}{ PP $1 \mathrm{~b}$} & \multicolumn{2}{|c|}{3.00000} & \multicolumn{2}{|r|}{0,07926} & & 0,23778 \\
\hline & & \multicolumn{2}{|c|}{3.00000} & \multicolumn{2}{|r|}{0,11392} & & 0,34176 \\
\hline \multicolumn{2}{|c|}{ PP $3 a$} & \multicolumn{2}{|c|}{4.20000} & \multicolumn{2}{|r|}{0,12186} & & 0,48744 \\
\hline \multirow{2}{*}{\multicolumn{2}{|c|}{ PP 3b }} & \multirow{2}{*}{\multicolumn{2}{|c|}{$\begin{array}{l}3.00000 \\
\text { Jumlah }\end{array}$}} & \multirow{2}{*}{\multicolumn{2}{|c|}{0,24153}} & & 0,72459 \\
\hline & & & & & & & 2.67835 \\
\hline
\end{tabular}

Dari table tersebut terlihat bahwa skor terbobot perspektif pertumbuhan \& pengembangan sebesar 2,67835.

5. Semua Perspektif

Skor, bobot, dan skor terbobot kinerja karyawan dari semua perspektif dapat dilihat pada table berikut :

\begin{tabular}{|c|c|c|c|c|c|}
\hline & & Keuangan & Pelanggan & Proses Bisnis & $\begin{array}{l}\text { Pertumbuhan \& } \\
\text { Perkem bengegn }\end{array}$ \\
\hline \multicolumn{2}{|l|}{$\begin{array}{l}\text { Keusangan } \\
\text { Pelanggan }\end{array}$} & $\begin{array}{l}1,000009 \\
0,33333\end{array}$ & $\begin{array}{l}3,00000 \\
1,00000\end{array}$ & $\begin{array}{l}3,00000 \\
0,20000\end{array}$ & $\begin{array}{l}5,00000 \\
0,20000\end{array}$ \\
\hline \multicolumn{2}{|l|}{ Proses Bisnis Intemal } & 0,33333 & 5,00000 & 1,00000 & 0,33333 \\
\hline \multirow{2}{*}{\multicolumn{6}{|c|}{$\begin{array}{l}\text { Pertumbitinan } \\
\text { perkembengan }\end{array}$}} \\
\hline & & & & 7,20000 & \\
\hline \multicolumn{6}{|c|}{ Table Normalisasi semua perspektif } \\
\hline & \multirow[t]{2}{*}{ Keuangan } & Pelangean & Proses Bisnis & Pertumbuhan \& & BOBOT \\
\hline & & & Internal & Perkembangan & \\
\hline Keuangan & \multirow{2}{*}{$\frac{0,53571}{0,17857}$} & 0,21428 & 0,41666 & 0,76530 & 0,48298 \\
\hline Pelangegan & & 0,07142 & 0,02777 & 0,03061 & 0,07709 \\
\hline Proses Bisnis & 0,17857 & 0,35714 & 0,13888 & 0,05101 & 0,18140 \\
\hline \multicolumn{6}{|l|}{ Internal } \\
\hline Pertumbuhan & 0,10714 & 0,35714 & 0,41666 & 0,15306 & 0,25850 \\
\hline \multicolumn{6}{|l|}{$\&$} \\
\hline \multicolumn{6}{|l|}{ perkembangan } \\
\hline \multirow{2}{*}{\multicolumn{6}{|c|}{ Table skor terbobot semua perspektif }} \\
\hline KPI & & & & & \\
\hline \multirow{2}{*}{$\begin{array}{l}\text { Keuangan } \\
\text { Pelangagan }\end{array}$} & \multicolumn{2}{|c|}{$\begin{array}{l}\text { SKOR } \\
1,89381\end{array}$} & 0,48298 & \multicolumn{2}{|l|}{0,91467} \\
\hline & \multicolumn{2}{|c|}{$\begin{array}{l}1,89381 \\
1,79741\end{array}$} & 0,07709 & 0,13856 & \\
\hline \multicolumn{2}{|l|}{ 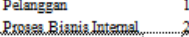 } & & 0.18140 & C.525120 & \\
\hline $\begin{array}{l}\text { Pertumbuhan } \\
\text { pertembangan }\end{array}$ & & & 0,25850 & 0,69235 & \\
\hline
\end{tabular}

Dari table tersebut terlihat bahwa skor terbobot dari semua perspektif sebesar 2,24678.

Keterangan : 
Kriteria penilaian dilakukan dengan acuan adalah : kurang.

- $\quad$ 1,00 - 1,50 adalah kinerja karyawan sangat

- 1,50 - 2,00 adalah kinerja karyawan kurang.

- 2,00 - 2,50 adalah kinerja karyawan baik.

- 2,50 - 3,00 adalah kinerja karyawan sangat baik.

Jadi skor kinerja sumber daya manusia pada Pondok Pesantren Assyafiiyah

Tamberu Agung Batumarmar 2,24678 menunjukkan bahwa kinerja karyawan baik.

\section{SIMPULAN DAN SARAN}

Berdasarkan analisis dari hasil penerapan metode HRSC sebagai analisis kinerja sumber daya manusia di Pondok Pesantren Assyafiiyah sebagai berikut :

1. Kinerja karyawan berdasarkan perspektif keuangan sebesar 1,89381 menunjukkan kurang baik. Kinerja karyawan berdasarkan perspektif pelanggan sebesar 1,79741 menunjukkan kurang baik. Perspektif proses bisnis internal sebesar 2,76297 menunjukkan sangat baik. Perspektif pertumbuhan dan perkembangan sebesar

2,67835 menunjukkan sangat baik. Sedangkan penilaian dari semua perspektif sebesar 2,24678, maka kinerja karyawan di Pondok Pesantren Assyafiiyah menunjukkan angka baik.

2. Faktor-faktor yang mempengaruhi optimalisasi kinerja SDM pada Pondok Pesan

Assyafiiyah meliputi hubungan kerja dan koordinasi yang baik antara pimpinan dan staff, system dan biokrasi yang tertata dengan baik, penghargaan dan pujian yang cukup terhadap capaian setiap karyawan baik dalam bentuk meteril maupun non- materiil, menjalin hubungan yang harmonis antara karyawan, serta pemanfaatan system informasi manajemen yang cukup memadai sehingga dapat dihasilkan data akurat dan akuntabel sebagai bahan dalam proses penetapan kebijakan.

Saran yang bisa disampaikan, sebagai berikut :

1. Melihat bahwa bidang keuangan masih kurang baik. Maka perlu melakukan perbaikan kinerja seperti efisiensi biaya yang dikeluarkan harus benar-benar sesuai kebutuhan dan mengesampingkan hal-hal yang dianggap tidak begitu memberikan dampak positif terhadap pondok pesanten. Pihak pimpinan harus melakukan pendekatan terhadap karyawan agar dapat dilihat kemampuan karyawan yang dianggap kurang optimal pada bidang apa saja, agar dapat diambil keputusan pengelolaan karyawan apakah harus mengadakan reshuffle karyawan menurut kemampuan yang dikuasai. Selain itu pada bidang keuangan perlu melakukan kerja sama dalam melakukan investasi terhadap pemasukan kas pondok pesantren.

2. Pada perspektif yang juga menunjukkan kinerja karyawan kurang baik perlu melakukan perbaikan dari berbagai bidang pemenuhan sarana prasarana, karena sarana prasarana mempunyai pengaruh yang sangat penting untuk menunjang berlangsungnya setiap kegiatan yang diadakan oleh pondok pesantren. Selain itu, perlu diadakan kerja sama dengan lembaga lain sebagai perbandingan kinerja karyawan yang nantinya akan memberikan pandangan lebih maju terhadap pondok pesantren.

3. Hendaknya manajemen Pondok pesantren Assyafiiyah meningkatkan kemampuan dalam mengelola perubahan dan budaya organisasi, meningkatkan keahlian karyawan, kompetensi pengetahuan dan keterampilan karyawan, serta meningkatkan kredibilitas karyawan, mengoptimalkan pengembangan modal sumber daya manusia melalui pendidikan dan pelatihan keterampilan yang lebih intensif dan berjenjang sesuai kebutuhan.

\section{DAFTAR PUSTAKA}

Fahmi, Irham. 2015. Manajemen Kinerja, Teori dan Aplikasi. Bandung: Alfabeta.

Certo, C. Samue. 1984. Management of Organizations and Human Resources.

Trinanto, Novirman. 2008. Manajemen Kinerja Sebagai Sebuah Sistem Dalam Meningkatkan Produktivitas Perusahaan. Jurnal Ekonomi dan Bisnis, Volume 3 Nomor 1.

Mardatillah, Yos Indra. 2013. Evaluasi Kinerja Manajemen Sumber Daya Manusia PT. Bank XYZ dengan Human Resource Scorecard. Jurnal Teknik Industri FT USU Vol 1, No.1 Januari.

Masruroh, Nisa. 2008. Pengukuran Kinerja Menggunakan Human Resources Scorecard dalam rangka Meningkatkan Kinerja di PT. Rajawali Tanjungsari. Jurnal TEKMAPRO Vol 3, No 1.Keuangan Menengah: Berbasis PSAK. 